Available online at

\title{
Soil Shear Strength Parameter Analysis Based On Behavior Analysis Of Landslide Case
}

\author{
D.W. Apriani ${ }^{1 *}$, U. Mustofa ${ }^{2}$, R. Hidayat ${ }^{3}$, \\ ${ }^{1 *}, 2,3$ Department of Civil Engineering and Planning Kalimantan Institute of Technology. \\ Email: ${ }^{1 *}$ dyahwahyuap@lecturer.itk.ac.id.
}

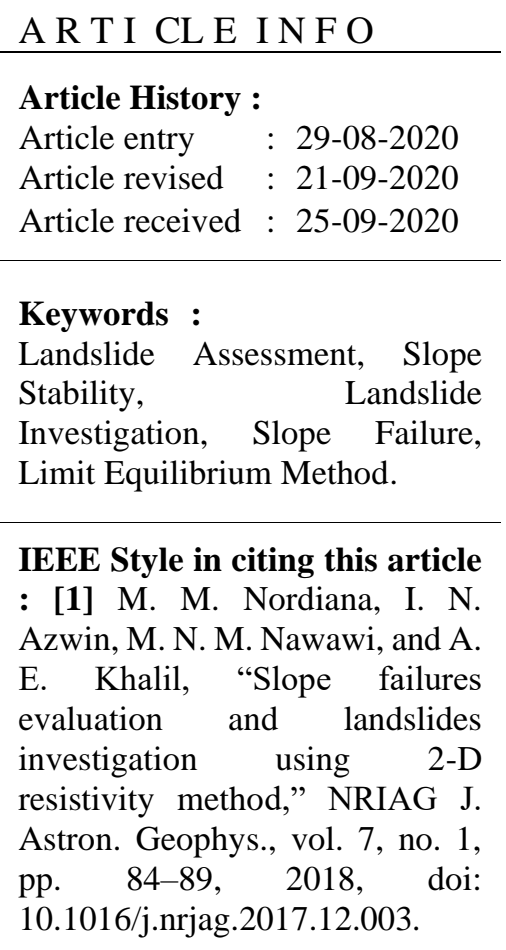

\begin{abstract}
A B S T R A C T
Slope failure is a complex event. It can provide useful information about the condition of soil parameters on the failed Slope in the same way it can provide an opportunity to evaluate other slopes stability. To evaluate the occurrence of slope landslides, unit weight data, and shear strength properties of soil are needed and methods of analysis, including failure mechanisms. One of the methods used to evaluate landslide events is reverse analysis. In this study, reverse carried out an analysis of landslides that occurred on the slopes of D-D 'and F-F' at the Integrated Campus Building of the Institut Teknologi Kalimantan. The limit equilibrium method is used to analyze the safety number of the slopes under review. From the results of the reverse analysis, it was obtained that the soil parameters at the time of collapse in the top layer resulted in the value of unit weight $(\gamma)=20 \mathrm{kN} / \mathrm{m}^{2}$, Cohesion $(c)=2 \mathrm{kPa}$, and Internal friction angle $(\varphi)=27^{\circ}$. Slope failure occurred due to an increase in soil volume weight value, as well as a decrease in soil shear strength parameters, namely Cohesion and internal friction angle.
\end{abstract}

\section{Introduction}

Slope failure and landslides are always associated with hilly areas and developing areas where infrastructure development is still rampant in these areas. Slope failure is a complex phenomenon that causes landslides and results in severe infrastructural, social, and economic damage. The prevalence of slope failure is caused by a combination of several factors, namely topography, climate, geology, and land use [1]. When a slope slides, there is a lot of useful information about the conditions of the Slope at the time of collapse as well as the opportunity to validate the existing stability analysis methods [2]. Slopes at campus area the Institut Teknologi Kalimantan often experience collapses on both reinforced and unreinforced slopes. 
For this reason, it is necessary to evaluate the occurrence of existing slope failure to determine the parameters that affect the incident. The evaluation was carried out using a reverse analysis of slope stability based on soil parameters in critical/ worst conditions. Soil parameters resulted from slope failure reverse analysis are more reliable than those obtained from laboratory tests or field tests [3]. It is simulated with an assisting program to assess slope stability at the Institut Teknologi Kalimantan campus area from these soil parameters. Modeling of events was carried out using the SLOPE / W program to review the factors causing landslides. The reverse analysis value can also be used efficiently to analyze the stability of other slopes with similar characteristics [4].

\section{Failure Evaluation and Slope Stability Methodology}

When Slope Fails by sliding, it gives useful information on the Slope's conditions at the time of the failure and an opportunity to validate the stability analysis method. Determining the conditions and establishing a suitable model of the Slope from a failure is termed back analysis or back-calculation. Back analysis of slope failures can provide functional relations between shear strength parameters $c$ and $\varphi$ for slopes of a homogeneous material with linear failure envelopes provided all the other parameters are known. The soil shear strength parameter analysis based on back analysis has been discussed by Zang et al. (2013), Hussain et al. (2010), Tang et al. (1999). Some of the factor that influences the back-calculated shear strength are engineering properties of the other materials in the cross-section, slope geometry at the time of failure, phreatic surface and porewater pressures present at the time of failure, the effect of rainfall, location of failure surface, and the existence of tension cracks.

\subsection{Back Analysis Method}

The reverse slide analysis is an analysis that creates the value of the slope safety factor (SF) close to or equal to 1.0 [5], which indicates landslide occurrence. This method is reliable and consistent for determining the soil parameters in the field when landslides occur[6]. In addition, the scale for reverse analysis is also much larger than the material obtained from field testing[7]. The purpose of the reverse analysis is to find soil parameters in the form of soil volume weight $(\gamma)$, Cohesion (c), and the angle of shear in the soil $(\phi)$, which causes the Slope to start sliding $(\mathrm{SF} \approx 1)$. The limitation of change in soil parameter values is obtained from the ranges of correlation values between soil types and soil parameters. To carry out a reverse analysis of the landslide to get an SF value close to or equal to 1.0, trial and error were made to 
the changes in each soil parameter from the laboratory test results using the Slope Geometry before the landslide occurs [8].

\subsection{Soil Parameters}

In the analysis of soil movement or landslides, the required soil parameters are obtained based on laboratory testing. The data includes the cohesion value, the inner friction angle, and the weight of the soil volume. The relationship between the internal shear angle and soil type is shown in Table 1.

Table 1. The relationship between soil type and soil friction angle

\begin{tabular}{lcc}
\hline Soil Classification (USCS) & \multicolumn{2}{c}{ Internal angel friction $(\varphi)$} \\
\hline GP (poorly Graded Gravel) & $30-35$ & $\left(\varphi^{\circ}\right)[10]$ \\
GW (Well Graded Grave) & $28-33$ & - \\
GM (Silty Gravel) & $30-35$ & - \\
GC (Clayey Gravel) & $30-35$ & - \\
SP (Poorly Graded Sand) & $27-37$ & - \\
SW (Well Graded Sand) & $28-33$ & - \\
SM (Silty Sand) & $24-32$ & - \\
SC (Clayey Sand) & $24-32$ & - \\
ML (Low Plasticity Silt) & $24-32$ & $18-32$ \\
MH (High Plasticity Silt) & $24-32$ & $18-32$ \\
CL (Low Plasticity Clay) & $15-20$ & $18-28$ \\
CH (High Plasticity Clay) & $15-30$ & $18-28$ \\
\hline
\end{tabular}

Source :[9] Budhu, 2010 and [10] Gupta, 2007

Cohesion is the attractive force between soil particles and the inner shear angle. Cohesion is a parameter of soil shear strength that determines the soil's resistance to deformation due to stresses acting on the soil, in this case, the soil's lateral motion. This deformation occurs due to a combination of critical conditions at normal stresses and shear stresses that are not by the planned safety factor. Cohesion and internal friction angle are mobilized in the same proportion simultaneously along the landslide plane[11]. The correlation between soil type and Cohesion is attached in Table 2 as follows.

Table 2. The relationship between soil type and Cohesion

\begin{tabular}{ll}
\hline Soil classification & Cohesion $(\mathrm{c})$ \\
& $\mathrm{kPa}[10]$ \\
\hline Gravel & 0 \\
Sand & 0 \\
Silt & $10-20$ \\
Clay & $10-20$ \\
\hline
\end{tabular}

Source : [10] Gupta, 2007 
The correlation between soil types based on soil classification and soil volume weight is attached in Table 3. as follows.

Table 3. The relationship between soil type and soil volume weight

\begin{tabular}{lcc}
\hline Soil Classification (USCS) & Unit weight $(\gamma)$ & $(\mathrm{kN} / \mathrm{m} 3)[9]$ \\
\hline GP (poorly Graded Gravel) & $30-35$ & - \\
GW (Well Graded Grave) & $28-33$ & - \\
GM (Silty Gravel) & $30-35$ & - \\
GC (Clayey Gravel) & $30-35$ & - \\
SP (Poorly Graded Sand) & $27-37$ & - \\
SW (Well Graded Sand) & $28-33$ & - \\
SM (Silty Sand) & $24-32$ & - \\
SC (Clayey Sand) & $24-32$ & - \\
ML (Low Plasticity Silt) & $24-32$ & $18-32$ \\
MH (High Plasticity Silt) & $24-32$ & $18-32$ \\
CL (Low Plasticity Clay) & $15-20$ & $18-28$ \\
CH (High Plasticity Clay) & $15-30$ & $18-28$ \\
\hline
\end{tabular}

Source : [9] Budhu, 2010 and [12] Coduto, 2000

\subsection{Limit Equilibrium Method}

Chosen The limit equilibrium method in slope analysis because it can model complex slope geometries, varying soil layers, and faster simulation time than the manual method. The difference in the analysis results of the value of safety values from finite element modeling and limit equilibrium modeling is not very significant[13]. SLOPE / W is a software product for calculating soil safety factors and rock/ soil slopes[14]. Slope / W uses the limit equilibrium method as a basis for analysis. The limit equilibrium method is important in slope stability analysis. This method calculates the safety factor by dividing the potential landslide field into several vertical slices. By using SLOPE/ W, a simple or complex problem analysis can be solved by one of the limit equilibrium methods provided, namely Fellenius, Bishop's simplified method, Janbu's simplified method, Morgenstern. -Price's method, Spencer's method, for various sloping surfaces, pore pressure conditions, soil properties, and concentrated loads. Despite various methods, Slope/ W has insignificant differences in the analysis result, which is less than 6\%[15]. In research and analysis of slope stability, especially SLOPE / W and SEEP / W have used many GeoStudio SLOPE / W software. Soil parameters that must be inputted in the GeoStudio software are Cohesion, soil volume weight, and soil shear angle.

\subsection{Safety Factor (SF)}

The safety figure equation is based on reverse analysis according to Equation 1 as 
follows [16].

$$
S F=\frac{\sum\left\{c_{i}+\left(\sigma_{i}-u_{i}\right) \tan \varphi_{i}\right\} l_{i}}{\sum \tau_{i} l_{i}}
$$

Equation 1

Where,

$\mathrm{c}=$ cohesion

$\sigma=$ normal stress

$\mathrm{u}=$ water pressure

$\varphi=$ friction angle

$\tau=$ mobilized shear stress

$1=$ length of rupture surface in layer

$\mathrm{i}=$ wedge being considered

Researches and comprehensive studies that have been carried out on slope sliding, classify the value of the Safety Factor (SF) in terms of the intensity of the slide, by the following

\section{Table 4.}

Table 4. Relationship between SF and landslide intensity [17]

\begin{tabular}{lc}
\hline Safety factors & Landslide occurence/ intensity \\
\hline $\mathrm{SF}<1.5$ & Slopes are in an unstable state \\
$\mathrm{SF}=1.5$ & Slopes are likely in an unstable state \\
$\mathrm{SF}>1.5$ & Slopes are stable \\
\hline
\end{tabular}

Souce : [17] Hardiyatmo, 2002

\section{Research Method}

\subsection{Data}

The analysis, soil parameter data, loading, and Slope geometry are needed in line with slope conditions. Obtained Soil parameter data through soil sampling carried out at 2 locations or slope points where the landslides happened, namely the slopes of Building E and Building F ITK Integrated Campus. Taking soil samples was carried out by hand boring from a depth of $50 \mathrm{~cm}$ to 1 meter to obtain undisturbed soil samples and hoeing the soil surface around the boring point to obtain disturbed soil samples. In addition to primary data, this study also used secondary soil data for the subgrade part of the Slope obtained from the 2019 ITK Integrated Campus Building Construction Planning data is shown in Figure 1. 


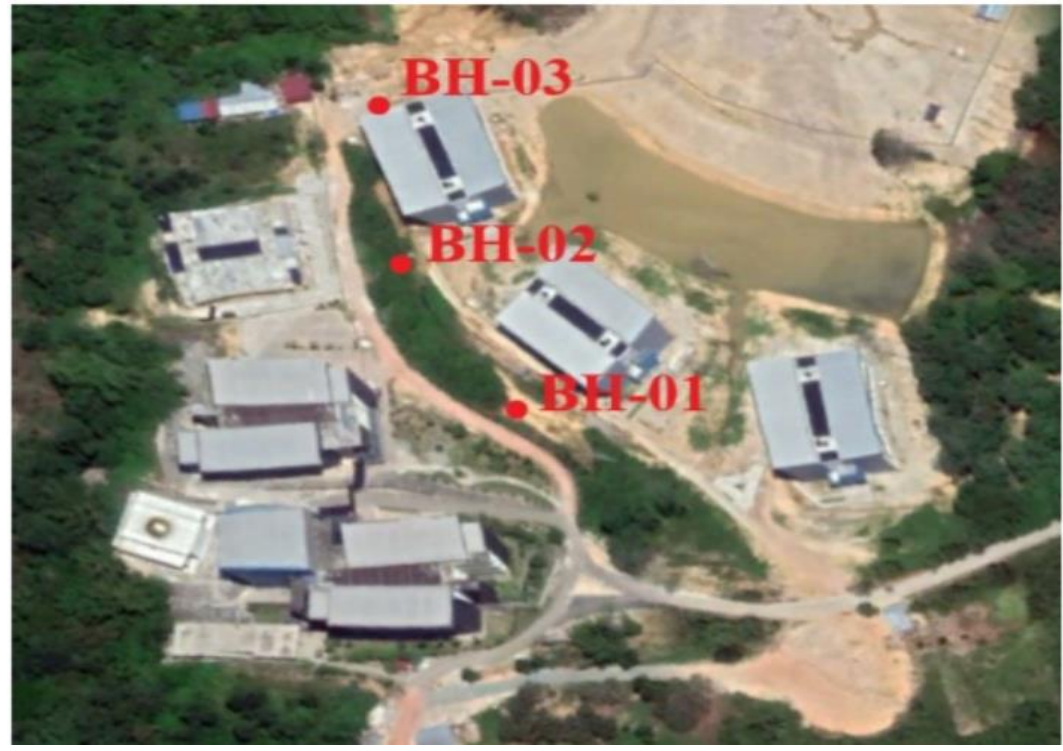

Source : Sampling point for soil analysis (Google Earth, 2020)

Figure 1. Soil sampling point

Obtained Slope geometry data was through a survey of 7 points along the slopes of the ITK Integrated Campus Building. Determined based The surveyed points' placement was on the results of visual field observations of steep slopes, slopes where landslides occurred, and slopes with potential soil movement. The location or point of observation on the slopes of the ITK Integrated Campus Building is shown in Figure 2.

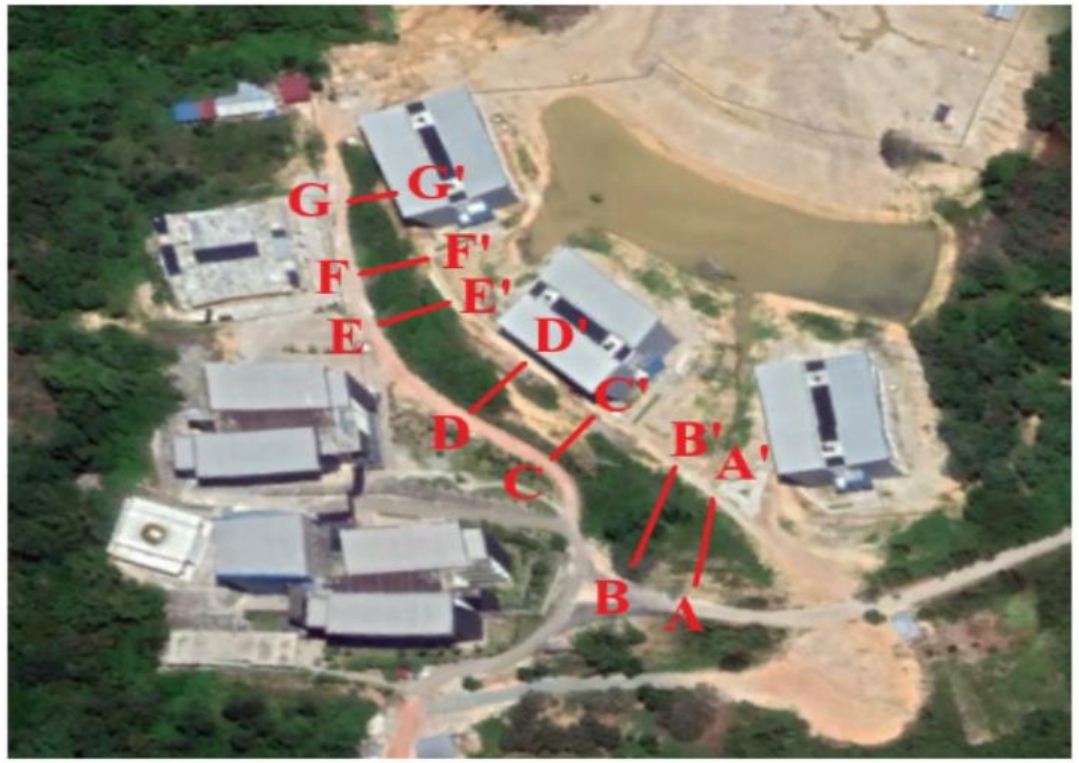

Source : Slope Point for geometry analysis (Google Earth, 2020)

Figure 2. Slope Survey Points 


\subsection{Failed Slope Stability Analysis}

Slope stability analysis aims to determine whether slopes that have experienced landslide still have the potential to collapse or not based on laboratory test results. In addition, this analysis also aims to determine the causes of sliding that occurred on these slopes. In this case, the slopes that have experienced failure at the ITK Integrated Campus Building area are Slope D-D 'and Slope F-F'. Can see in the form of slope failures in Figure 3.

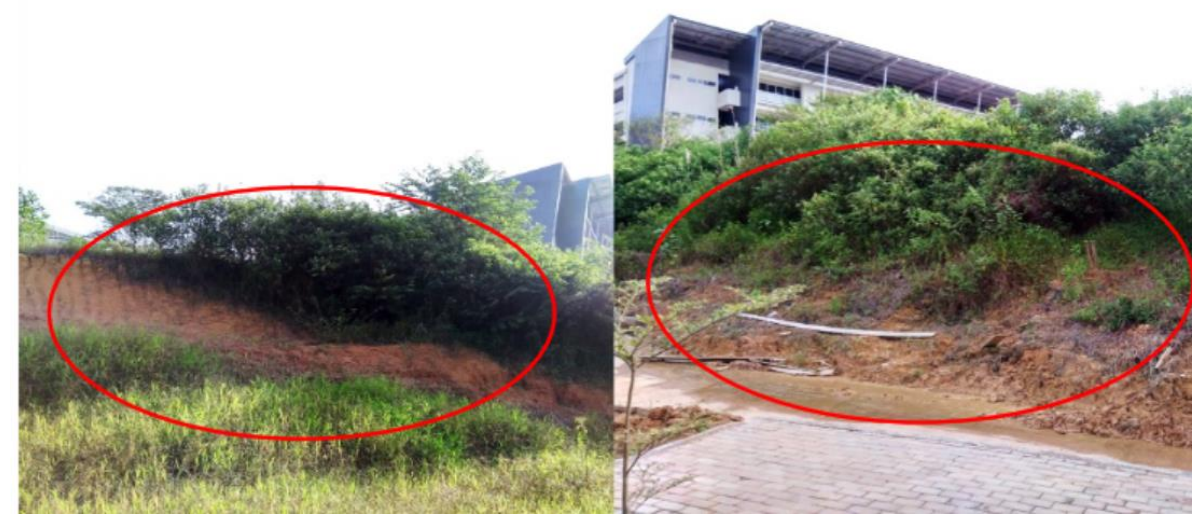

Source : Field Survey at slope failures in March 2020

Figure 3. Slope Failures at Slope D-D 'and Slope F-F'

Furthermore, the existing stability analysis of landslides was carried out using the SLOPE / W program. This analysis used soil data from the laboratory test results after the landslide occurred adjusted to the location of soil sampling, slope loading of $12 \mathrm{kPa}$.[18], as well as the geometric shape of the Slope after the landslide occurred. The topsoil/ layer 1 on Slope D-D' used BH-01 data, and its lower layer/ layer 2 used BH-03 data. In contrast, the topsoil/ layer 1 of Slope F-F used BH-02 data, and its lower layer/ layer 2 used BH-03 data. The next step was to analyze the slope geometry before the landslide occurs. Given the limited data on the Slope's geometric shape before sliding on Slope D-D 'and Slope F-F,' an approach was made for the geometric shape of the slopes by adjusting the shape of the Slope to conditions around the Slope that have not experienced failure. Based on direct observations in the field, without changing the Slope's height and initial length could estimate the slope geometry.

\subsection{Landslide Reverse Analysis}

The reverse analysis of the landslide aims to find soil parameters in the form of soil volume weight $(\gamma)$, Cohesion (c), and the angle of shear in the soil $(\phi)$, which cause a landslide to start or occur $(\mathrm{SF} \approx 1)$. The limitation of change in soil parameter values is obtained from the ranges of correlation values between soil types and soil parameters. The range of correlation Soil Shear Strength Parameter Analysis Based On Behavior Analysis Of Landslide Case http://dx.doi.org/10.30737/ukarst.v3i2 
The values for these parameters can be seen in Table 1 to Table 3. To carry out a reverse analysis of the landslide in order to get an SF value close to or equal to 1.0, it is done by trial and error to the changes in each soil parameter from the laboratory test results using the slope geometry before the landslide occurs. Thus, there are 11 variations in slope modeling to obtain soil parameters when the $\mathrm{SF}$ value $\approx 1.0$. The stability of existing slopes that have experienced landslides is carried out using the SLOPE/ W program. The modeling variation to determine the soil parameters in the case of landslides begins with the determination of the number of the slope safety factors before landslides using laboratory test results and slope geometry data prior to landslides, then continues with reviewing changes in the number of safety factors against:

1 Increase in soil volume weight value $(\gamma)$ (1st variation)

2 The decrease in soil volume weight value $(\gamma)$ (2nd variation)

3 Increase in soil cohesion value (c) (3rd variation)

4 Decrease in soil cohesion value (c) (4th variation)

5 Increase in soil shear angle value $(\phi)$ (5th variation)

6 Decrease in soil shear angle value $(\phi)$ (6th variation)

7 Combination of increasing soil volume weight, Cohesion and shear angle (7th variation)

8 Combination of decreasing soil volume weight, Cohesion and shear angle (8th variation)

9 Combination of increasing soil volume weight value, decreasing soil cohesion and shear angle (9th variation)

10 A combination of decreasing soil volume weight, increasing soil cohesion, and shear angle (10th variation).

11 Critical condition, conditions for determining the combination of soil volume weight, Cohesion, and shear angle values for each soil layer which results in a value of $\mathrm{SF} \approx 1$ that indicates the Slope begins to slide (11th variation)

After obtaining soil parameters in critical condition $(\mathrm{SF} \approx 1)$, slope stability analysis is then performed at other surveyed points that have not experienced landslides. If these points produce an SF value $<1.5$, the slopes will have the potential of landslides.

\section{Results and Discussions}

Based on the SLOPE/W simulation for slope conditions after experiencing landslides, the SF value of Slope D-D' is 2,937 in accordance with Figure 4. Meanwhile, the SF value of

Slope F-F' is 3,764 in accordance with Figure 5. Thus, it can be concluded that the two slopes 

are in a safe condition.

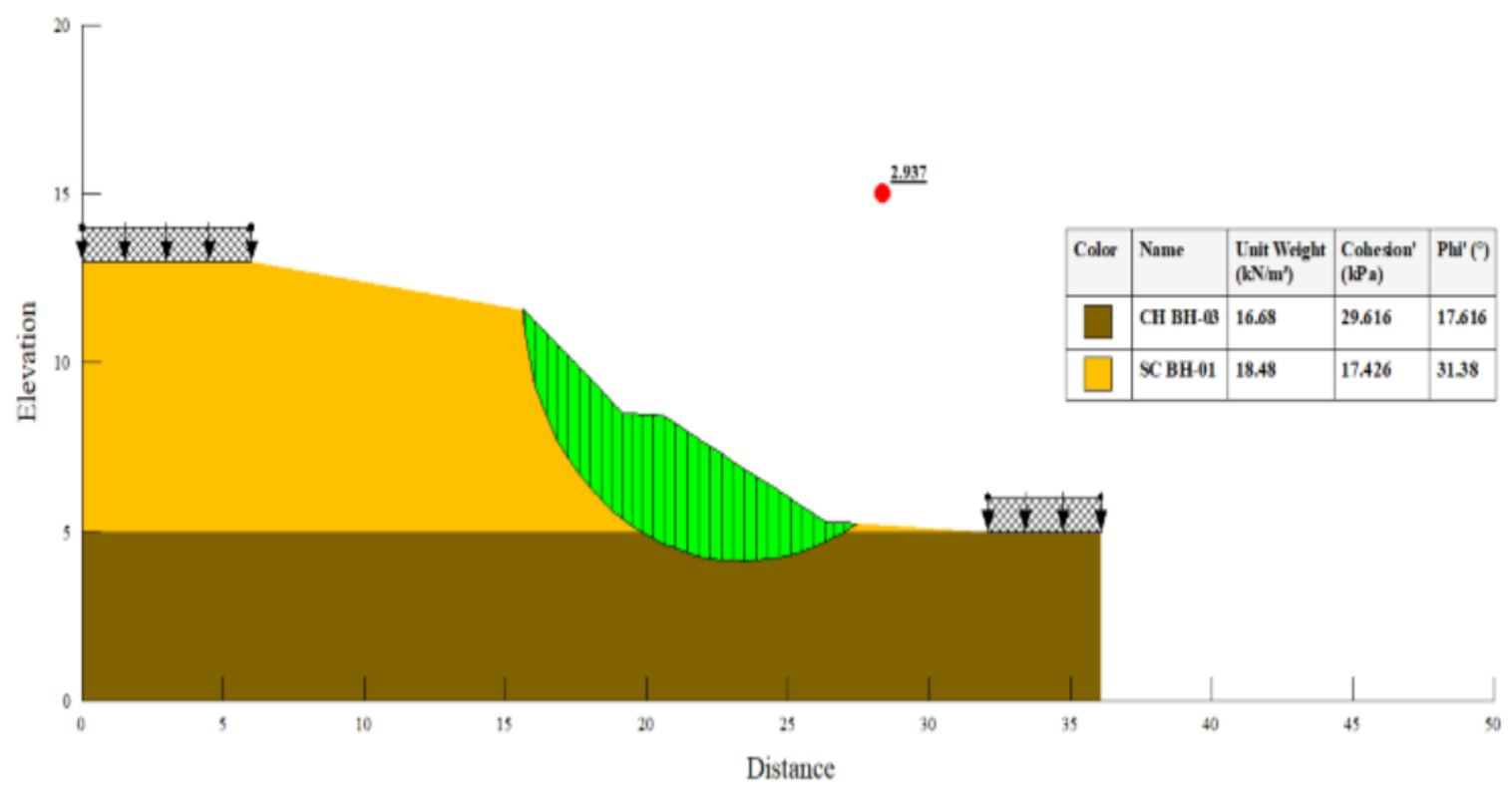

Source : Simulation result for Slope Failure Analysis (Slope/W)

Figure 4 Safety Factor of Slope D-D 'after landslides

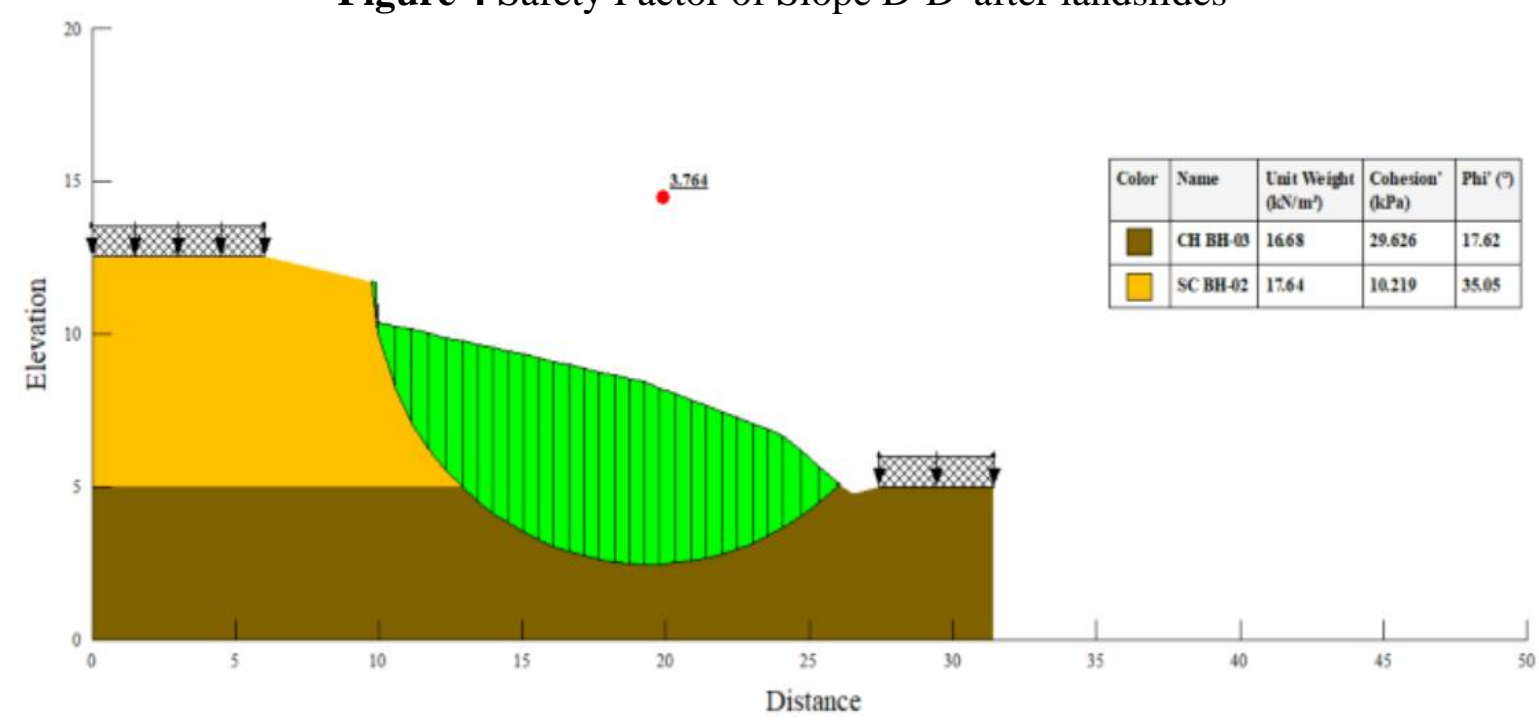

Source : Simulation result for Slope Failure Analysis (Slope/W)

Figure 5 Safety Factor of Slope F-F' after landslides

On the other hand, the value of the safety factor from the SLOPE/ W analysis which was analyzed with the initial slope conditions before the landslide occured, results in the SF value of 2,332 for Slope D-D' and Slope F-F' in accordance with Figure 6 and Figure 7 which indicates that the two slopes were in a safe condition before the landslide occurred. 


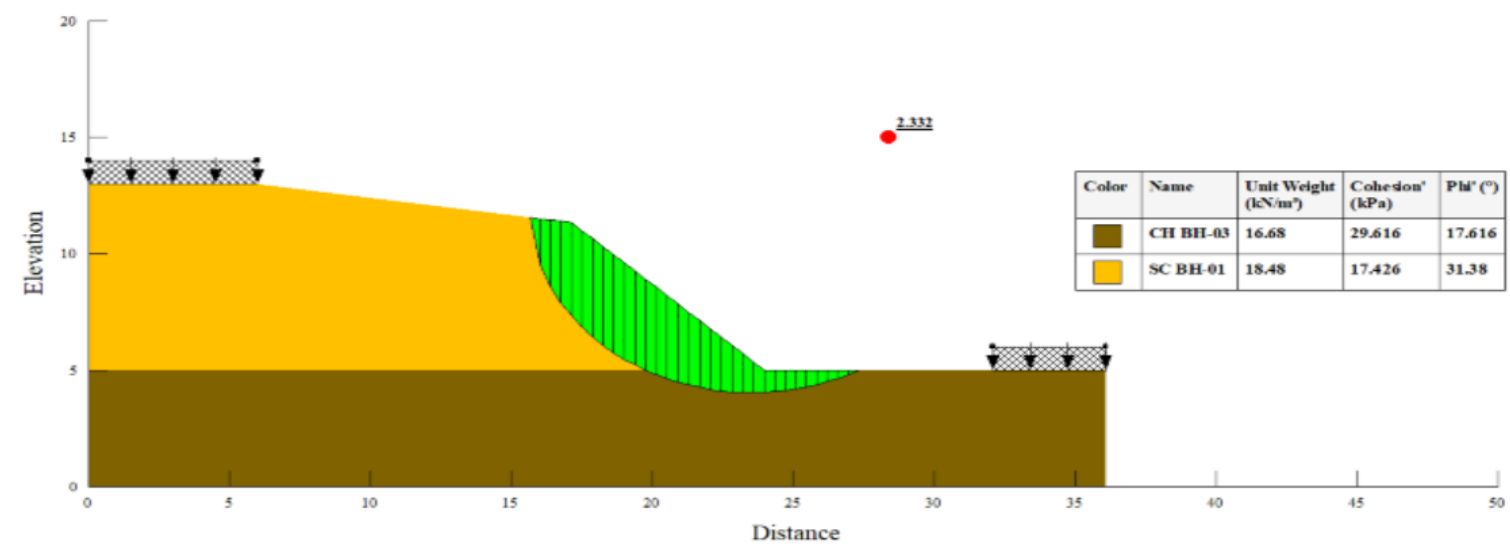

Source : Simulation result for Slope Failure Analysis (Slope/W)

Figure 6 Safety Factor of Slope D-D ' before landslides

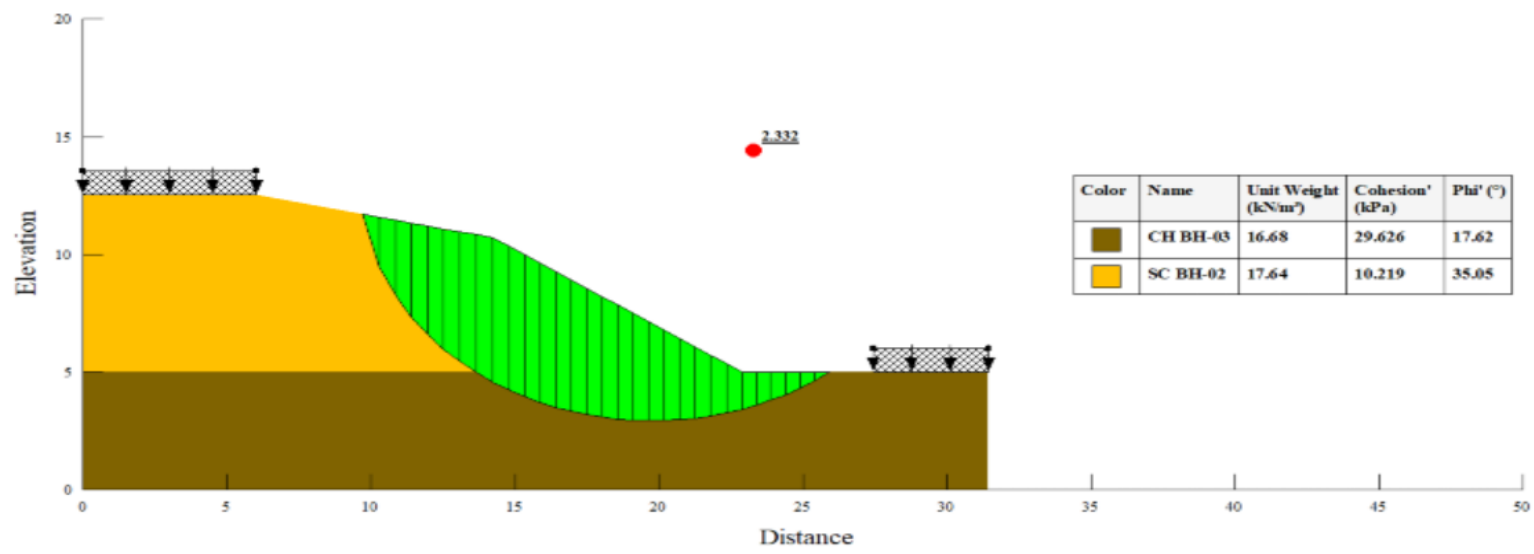

Source : Simulation result for Slope Failure Analysis (Slope/W)

Figure 7 Safety Factor of Slope F-F ' before landslides

Although the slope conditions are still safe, the SF value for both slopes has decreased by using the same soil parameters but with different slope geometries. The decrease in the value of SF is caused by changes in slope angles that affect the stability of the soil. The steeper the slope, the greater the lateral earth pressure/ driving force will be exerted to move the slope [19]. Thus, this causes the SF value to be smaller. Given that the obtained SF value is in a safe condition (SF> 1.5) in the sense that landslides shall not have occurred, slope failures have occurred in the said location with landslides in the same area. Therefore, to correlate real cases in the field with calculations, reverse analysis is necessary. A reverse analysis is carried out on the Slope geometry before the landslide happened, with varying soil parameters. Trial and error with 11 variations were carried out to obtain soil parameters during landslides with results that match the criteria shown in Table 5. 
Table 5. Result of analysis behind critical condition

\begin{tabular}{|c|c|c|c|c|c|c|c|c|c|}
\hline \multirow{3}{*}{$\begin{array}{l}\text { Vari } \\
\text { ation } \\
\text { num } \\
\text { ber- }\end{array}$} & \multirow{3}{*}{$\begin{array}{c}\text { Conditio } \\
\text { n / } \\
\text { slopes }\end{array}$} & \multicolumn{6}{|c|}{ Soil Parameters } & \multirow[t]{3}{*}{ Analysis results } & \multirow[t]{3}{*}{ SF } \\
\hline & & \multicolumn{3}{|c|}{ Layer 1} & \multicolumn{3}{|c|}{ Layer 2} & & \\
\hline & & $\begin{array}{c}\gamma \\
\left(\mathrm{kN} / \mathrm{m}^{3}\right)\end{array}$ & $\begin{array}{l}\phi \\
\circ \\
\end{array}$ & $\begin{array}{c}\mathrm{c} \\
\mathrm{kpa}\end{array}$ & $\begin{array}{c}\gamma \\
\left(\mathrm{kN} / \mathrm{m}^{3}\right)\end{array}$ & $\begin{array}{l}\Phi \\
\circ\end{array}$ & $\begin{array}{c}\mathrm{C} \\
\mathrm{kPa}\end{array}$ & & \\
\hline 11 & $\begin{array}{l}\text { Critical/ } \\
\text { D-D ' }\end{array}$ & 20 & 4 & 27 & 21 & 10 & 15 & - & $\begin{array}{c}0.99 \\
8\end{array}$ \\
\hline 11 & $\begin{array}{l}\text { Critical/ } \\
\text { F-F }^{\prime}\end{array}$ & 20 & 2 & 27 & 22 & 10 & 10 & & 1 \\
\hline
\end{tabular}

Source : Based on Author Analysis

Changes in soil parameter values such as increasing soil volume weight and decreasing soil cohesion and shear angles can affect a slope's stability. This is proven based on the results of reverse analysis by conducting trial and error through 11 existing variations, which shows changes in the three parameter conditions and results in a smaller safety factor than the slope conditions before the landslides occurred using the laboratory test results. Increasing soil volume weight and decreasing soil cohesion and shear angle are caused by water's influence such as rain[20]. To find out which parameters will be used for planning, the soil parameter values are shown in Table 5. Result of analysis behind critical condition will be used to analyze all slopes under review. Recapitulation of SF values based on soil parameters in critical conditions can be seen in Table $\mathbf{6}$ as follows:

Table 6 Slope safety factor based on soil parameters from reverse analysis

\begin{tabular}{|c|c|c|c|}
\hline Slope & Soil data from slopes & Safety Factor/ W & Remarks \\
\hline $\mathrm{A} \mathrm{A}^{\prime}$ & Critical D-D ' & 2,467 & Safe \\
\hline $\mathrm{B}-\mathrm{B}^{\prime}$ & & 2,526 & Safe \\
\hline${\mathrm{C}-\mathrm{C}^{\prime}}^{\prime}$ & & 1,401 & Not safe \\
\hline D-D ' & & 0.998 & Not safe \\
\hline${\mathrm{E}-\mathrm{E}^{\prime}}^{\prime}$ & & 1,258 & Not safe \\
\hline $\mathrm{F}^{-F^{\prime}}$ & & 1,210 & Not safe \\
\hline G-G ' & & 1,319 & Not safe \\
\hline A A $A^{\prime}$ & Critical F-F' & 1,929 & Safe \\
\hline B-B ' & & 1,961 & Safe \\
\hline C-C ${ }^{\prime}$ & & 1,108 & Not safe \\
\hline D-D ' & & 0.936 & Not safe \\
\hline E-E' & & 1,051 & Not safe \\
\hline $\mathrm{F}^{-\mathrm{F}^{\prime}}$ & & 1,000 & Not safe \\
\hline G-G ' & & 1,095 & Not safe \\
\hline
\end{tabular}

Source : Based on Author Analysis 
The recapitulation of the analysis results on Table 6 shows that the use of soil parameters from the reverse analysis of Slope F-F ' results in a smaller SF value than the soil parameters from the reverse analysis Slope D-D'. Therefore, in the slope reinforcement planning analysis, the soil parameters from the reverse Slope F-F 'analysis are used as soil data in the worst conditions and to anticipate possible slope failures.

\section{Conclusion and Recommendation}

\subsection{Conclusion}

The value of the soil shear strength parameter is based on the reverse analysis of landslides on the slopes of the Institut Teknologi Kalimantan Integrated Campus Building. The upper layer produces a unit weight value $(\gamma)$ of $20 \mathrm{kN} / \mathrm{m} 2$, Cohesion $(\mathrm{c})=2 \mathrm{kPa}$ and internal friction angle $(\varphi)=27^{\circ}$, while the subgrade produces a unit weight value of $(\gamma) 20 \mathrm{kN} / \mathrm{m} 2$, Cohesion $(\mathrm{c})=2 \mathrm{kPa}$ and internal friction angle $(\varphi)=27^{\circ}$. Slope failures occur due to an increase in soil volume weight value and a decrease in soil shear strength parameters, namely Cohesion and internal friction angle.

\subsection{Recommendation}

This research can be developed by assessing the stability of the slopes in the wider Institut Teknologi Kalimantan area based on soil parameters in the critical conditions where landslides have occurred. Therefore, areas with high potential and risk of slope failure can be mapped, and mitigation efforts can be determined on slopes with high potential and high risk of slope failure. 


\section{References}

[1] M. M. Nordiana, I. N. Azwin, M. N. M. Nawawi, and A. E. Khalil, "Slope failures evaluation and landslides investigation using 2-D resistivity method," NRIAG J. Astron. Geophys., vol. 7, no. 1, pp. 84-89, 2018, doi: 10.1016/j.nrjag.2017.12.003.

[2] J. M. Duncan, S. G. Wright, and Thomas L. Brandon, Soil Strength and Slope Stability. John Wiley \& Sons, Inc, 2014.

[3] J. Jiang and T. Yamagami, "Charts for estimating strength parameters from slips in homogeneous slopes," Comput. Geotech., no. 33(6-7), pp. 294-304, 2006.

[4] J. Bojorque Iñeguez, "Back-analysis of slope failures by numerical techniques," Electron. J. Geotech. Eng., vol. 21, no. 2, pp. 615-625, 2016.

[5] J.M. Duncan and D. S. Timothy, "Stability performance of slopes and embankments," I Proc., no. June 29-July1, pp. 890-904, 1992, [Online]. Available: https://cedb.asce.org/CEDBsearch/record.jsp?dockey=0077203.

[6] Jagriti Mandal, Sruti Narwal, and Dr. S. S. Gupte, "Back Analysis of Failed Slopes - A Case Study," Int. J. Eng. Res., vol. V6, no. 05, pp. 1070-1078, 2017, doi: 10.17577/ijertv6is050366.

[7] R. B. Gilbert, G. W. Stephen, and L. Eric, "Uncertainty in back analysis of slopes: Kettleman Hills case history," J. Geotech. Geoenvironmental Eng., vol. 12, no. 124, pp. 1167-1176, 1998.

[8] K. Zang, P. CAO, and R. BAO, "Rigorous back analysis of shear strength parameters of landslide slip," Trans. Nonferrous Met. Soc. China, vol. 23, no. 5, pp. 1459-1464, 2013, [Online]. Available: https://www.sciencedirect.com/science/article/abs/pii/S1003632613626175.

[9] M. Budhu, Soil Mechanics and Foundations, 3rd ed. 2010.

[10] S. Gupta, A. Ranaivoson, T. Edil, C. Benson, and A. Sawangsuriya, "Pavement design using unsaturated soil technology," Minnesota Dep. Transp. Res. Serv. Sect., p. 246, 2007, [Online]. Available: http://www.lrrb.org/PDF/200711.pdf.

[11] H. C. Hardiyatmo, Soil Mechanics 2, 5th ed. Yogyakarta: Gadjah Mada University Press, 2014.

[12] D. P. Coduto, "Foundation Design_Principles and Practices (2nd Edition)-Prentice Hall 
(2000).pdf.” p. 484, 2001.

[13] K. Baba, L. Bahi, L. Ouadif, and A. Akhssas, "Slope Stability Evaluations by Limit Equilibrium and Finite Element Methods Applied to a Railway in the Moroccan Rif," Open J. Civ. Eng., vol. 02, no. 01, pp. 27-32, 2012, doi: 10.4236/ojce.2012.21005.

[14] GEO-SLOPE, "Stability modeling with Slope/W," ... Methodol. Calgary, Canada, GeoSlope $W \quad$..., no. June, 2012, [Online]. Available: http://www.eng.uwo.ca/people/tnewson/Lectures/SLOPEW Engineering Book.pdf.

[15] J. M. Abbas and Z. A. Mutiny, "Slope Stability Analysis for Earth Dams Using (GeoSlope/W)," Diyala J. Eng. Sci., vol. 11, no. 1, pp. 70-81, 2018, doi: 10.26367/DJES/VOL.11/NO.1/12.

[16] R. Deschamps and G. Yankey, "Limitations in the Back-Analysis of Strength from Failures," J. Geotech. Geoenvironmental Eng., vol. 132, no. 4, pp. 01-10, 2006, [Online]. Available: https://ascelibrary.org/doi/pdf/10.1061/\%28ASCE\%291090$0241 \% 282006 \% 29132 \% 3 \mathrm{~A} 4 \% 28532 \% 29$.

[17] H. C. Hardiyatmo, Foundation Engineering 2, 2nd ed. Yogyakarta: Gadjah Mada University Press, 2002.

[18] Department of Public Works, "Slope Failure Management Engineering in Residual Soil and Rock," p. 98, 2005.

[19] N. Fadilah, U. Arsyad, and A. S. Soma, "Analysis of Landslide Hazard Level Using Frequency Ratio Method in the Bialo River Basin," Perennial, vol. 15, no. 1, p. 42, 2019, doi: 10.24259/perennial.v15i1.6317.

[20] R. T. Audinno, M. S. N. Ilham, A. Gunawan, and A. E. Nandro, "Analysis of Physical and Mechanical Properties of Rocks in the Balikpapan, East Kalimantan," Proc. Natl. Semin. Earth, pp. 116-129, 2014. 